\title{
Effect of ultrasound-guided peripheral nerve blocks of the abdominal wall on pain relief after laparoscopic cholecystectomy
}

This article was published in the following Dove Press journal:

Journal of Pain Research

\author{
Lining $\mathrm{Wu}^{\prime}$ \\ Liangchun $\mathrm{Wu}^{2}$ \\ Hao Sun' \\ Chunshan Dong' \\ Junma $\mathrm{Yu}^{\prime}$
}

'Department of Anesthesiology, The First People's Hospital of Hefei, Anhui Medical University, Hefei 23006I,

People's Republic of China; ${ }^{2}$ Department of Anesthesiology, Anhui Provincial People's Armed Police General Hospital, Hefei 23004I, People's Republic of China
Purpose: The aim of this study was to compare the effect of an ultrasound-guided transversus abdominis plane block (TAPB) and rectus sheath block (RSB) combination, an ultrasound-guided posterior TAP block combined with the local anesthetic infiltration (LAI) and LAI alone on pain relief after laparoscopic cholecystectomy (LC).

Patients and methods: One hundred eighty patients who were American Society of Anesthesiologists class $\mathrm{I}$ or $\Pi$ were included in this randomized, double-blind, noninferiority study. All patients underwent three-port LC and were divided into 3 groups. The LAI group had ropivacaine mixed with dexmedetomidine injected around the trocar entrance site preoperatively. The TL group underwent ultrasound-guided posterior TAPB combined with LAI, and the TR group underwent ultrasound-guided TAPB combined with RSB. Postoperative pain was evaluated at the first, 4th, 8th, 24th, and 48th hours. If the visual analogue scale (VAS) score (including incisional pain, visceral pain or shoulder pain) was $>3$, intravenous dezocine $(0.05 \mathrm{mg} / \mathrm{kg})$ was injected slowly. Sleep quality, total consumption of dezocine and time to unassisted walking were recorded. The Global Satisfaction Score (GSS) for analgesia was also assessed within $48 \mathrm{hrs}$.

Results: No difference was found in sleep quality, time to unassisted walking, or requirement for dezocine. We also found no difference in VAS scores at each time point within 48 hrs after LC among the 3 groups, but the GSS for analgesia in the LAI group was significantly increased within 48 hrs compared with the other two groups.

Conclusion: Ultrasound-guided peripheral nerve blocks of the abdominal wall can significantly relieve postoperative pain in patients undergoing LC; however, patients receiving LAI expressed more satisfaction than patients in whom other methods were used. LAI is an easy and effective method that can be recommended for routine clinical practice in LC patients who are not converted to an open procedure.

Keywords: laparoscopic cholecystectomy, postoperative pain, local anesthetics, TAPB, trocar-site anesthesia

\section{Introduction}

A large data analysis revealed that the unplanned admission and readmission rates after laparoscopic cholecystectomy (LC) are very low; however, pain continues to be an important issue after LC that results in prolonged admissions or readmissions. ${ }^{1}$ Khan et al concluded that an ultrasound-guided subcostal transversus abdominis plane block (TAPB) provides better postoperative analgesia compared to the a posterior TAPB for LC, and both of these approaches
Correspondence: Junma Yu Department of Anesthesiology, The First People's Hospital of Hefei, Anhui Medical University, Huaihe Road 390, Hefei 23006I, People's Republic of China Tel +865 5162183386

Email majuny163@I63.com 
improve patient outcomes in terms of early recovery and discharge from hospital. ${ }^{2}$ However, the additional effect of analgesia with ultrasound-guided posterior TAPB is presumed to be caused by a reduction in visceral pain related to sympathetic nerve block. ${ }^{3}$ A rectus sheath block (RSB) can provide analgesia for small subxiphoid incision where the nerves from T6-T8 course. ${ }^{4,5}$ Thus, an RSB might be useful for pain control for incision in the subxiphoid area. Another study reported that the combination of an RSB and TAPB effectively controlled pain after LC and decreased numeric rating scale scores. ${ }^{6}$ Local anesthetic infiltration (LAI) at the trocar entrance sites is a technique that has been shown to decrease pain and opioid requirements after LC and is commonly used by surgeons; furthermore, we concluded that incisional infiltration of ropivacaine combined with dexmedetomidine could significantly reduce postoperative pain and analgesic requirement; this technique also facilitated early mobilization and enhanced the postoperative analgesic effects and sleep quality during the first night after LC without increasing the incidence of surgical adverse events. ${ }^{7}$

We hypothesized that ultrasound-guided peripheral nerve blocks of the abdominal wall would lead to lower postoperative pain scores after LC than LAI of the trocar insertion sites.

\section{Materials and methods}

This randomized, double-blind, non-inferiority study was approved by the Institutional Research Ethics Committee of The First People's Hospital of Hefei (No. 2015-11) and already registered in the Chinese Clinical Trial Registry (ChiCTR-IOR-16009912). Written informed consent was obtained from all study subjects, and the study was conducted in accordance with the Declaration of Helsinki. The patients and staff responsible for the data collection were blinded to the study.

The exclusion criteria were as follows: patients with a body mass index $(\mathrm{BMI}) \geq 30 \mathrm{~kg} / \mathrm{m}^{2}$, age $<18$ years or $>65$ years, hepatic or renal disease, coagulopathy, history of alcohol or drug abuse, ASA physical status III or greater, pregnant patients, patients with a past medical history of chronic pain (such as fibromyalgia or low back pain), patients at risk for taking NSAIDs, those with allergies to medication or those receiving medication treatment within 3 months (dexmedetomidine and ropivacaine), and patients who could not obey commands were excluded from our study. Moreover, patients were excluded if the surgery was converted to an open procedure or a drainage catheter was placed.

All patients who underwent 3-port LC procedures performed by surgeons trained in laparoscopy were randomly divided into 3 groups. Group assignments were placed inside numbered opaque envelopes. The LAI group had ropivacaine mixed with dexmedetomidine injected around the trocar entrance sites. The TL group underwent ultrasound-guided posterior TAPB combined with LAI, and the TR group underwent ultrasound-guided subcostal TAPB combined with RSB. All injections were performed before skin incision. The LAI group received preincisional infiltration of $0.5 \%$ ropivacaine mixed with $1 \mu \mathrm{g} / \mathrm{kg}$ dexmedetomidine in a total volume of $30 \mathrm{ml}$, as in the previous study. ${ }^{7}$ The TL and TR groups received $0.25 \%$ ropivacaine mixed with $1 \mu \mathrm{g} / \mathrm{kg}$ of dexmedetomidine in a total volume of $60 \mathrm{ml}$ (30 ml for bilateral posterior TAPB and preincisional infiltration in the TL group). In addition, $40 \mathrm{ml}$ of the mixture was used for bilateral TAPB and $20 \mathrm{ml}$ for bilateral RSB in the TR group. The ultrasound-guided peripheral nerve blocks of the abdominal wall were performed by anesthesiologists with significant experience with this technique.

During the preoperative interview, the patients were introduced to the concept of the visual analogue scale (VAS), in which a $10-\mathrm{cm}$ vertical score ranges from $0=$ no pain to $10=$ worst pain imaginable. The VAS was used to assess the postoperative pain of each patient at different time points after surgery. The effect on pain intensity was evaluated with the VAS and the amount of analgesics used.

All patients underwent general anesthesia with the same protocol. Intraoperative continuous monitoring included a five-lead electrocardiogram, noninvasive blood pressure, pulse oxygen saturation, Narcotrend (Narcotrend-Compact, MT Monitior Technik GmbH \& Co., Bad Bramstedt, Germany) parameters and end-tidal $\mathrm{CO}_{2}$. No patient received premedication, and venous access was established for infusion of lactated Ringer's solution when they arrived at the operating room. All patients received an intravenous injection of $1.5 \mathrm{mg} / \mathrm{kg}$ of flurbiprofen axetil (a type of NSAID) $10 \mathrm{~min}$ before anesthesia induction, which was repeated $6 \mathrm{~h}$ after surgery. Then, anesthesia was induced with $1 \mu \mathrm{g} / \mathrm{kg}$ of remifentanil and $1.5-2.5 \mathrm{mg} / \mathrm{kg}$ of propofol, followed by $0.15 \mathrm{mg} / \mathrm{kg}$ of cisatracurium to facilitate tracheal intubation. The infusions of remifentanil and propofol were continued at $0.1-0.5 \mu \mathrm{g} \cdot \mathrm{kg}^{-1} \cdot \mathrm{h}^{-1}$ and $3-12 \mu \mathrm{g} \cdot \mathrm{kg}^{-1} \cdot \mathrm{h}^{-1}$, respectively, 
immediately after the loading doses were administered to maintain the Narcotrend Index between 40 and 60 during the procedure. After endotracheal intubation, all patients were provided with mechanical ventilation. Minute ventilation was adjusted to keep end-tidal $\mathrm{CO}_{2}$ at $35-45 \mathrm{mmHg}$. During laparoscopy, the intra-abdominal pressure of the $\mathrm{CO}_{2}$ pneumoperitoneum was maintained at $12 \mathrm{mmHg}$. $\mathrm{CO}_{2}$ was carefully excreted at the end of surgery by manual compression of the abdomen through the open trocars. Residual neuromuscular blockade was reversed with $1 \mathrm{mg} / \mathrm{kg}$ of neostigmine, and $0.5 \mathrm{mg}$ of atropine was administered. During closure of the skin, tropisetron (2 mg) was administered intravenously.

The VAS score was recorded at the following time points: $1 \mathrm{hr}$ (T1), $4 \mathrm{hrs}$ (T2), $8 \mathrm{hrs}$ (T3), $24 \mathrm{hrs}$ (T4), and $48 \mathrm{hrs}$ (T5) after surgery. If the VAS score (including incisional pain, visceral pain or shoulder pain) was $>3$, $5 \mathrm{mg}$ of dezocine was injected intramuscularly.

Awakening time from anesthesia, time to unassisted walking, sleep quality (if the patient awoke because of pain on the first postoperative night or not), the total consumption of dezocine, and the number of patients experiencing postoperative nausea and vomiting (PONV) were recorded. The Global Satisfaction Score $(\mathrm{GSS})^{8}$ was also assessed within $48 \mathrm{hrs}$. The GSS was used to evaluate patients' satisfaction with pain control and was reported as follows: "poor $=1$ ", "fair $=2 "$, "good $=3$ ", or "very good $=4$ ". The number of patients who experienced PONV was also recorded. Patients were hospitalized for up to $48 \mathrm{hrs}$ as part of our routine practice.

In a pilot study, we found that patients receiving LAI expressed more satisfaction than patients in whom other methods were used $(n=30$ patients, 10 patients per group, GSS: $3.60 \pm 0.5,3.10 \pm 0.7$ and $3.0 \pm 0.9$, respectively). To achieve $80 \%$ power and an $\alpha$-error of $5 \%$, the total sample size was 144 , as calculated using G*Power 3.1.9.4 software. Then, a total of 180 American Society of Anesthesiologists (ASA) status I or II patients were scheduled for elective LC with 3 trocar sites under general anesthesia and were enrolled in this study.

Data are expressed as the mean \pm standard deviation (SD) or mean \pm standard error of the mean (SEM). Parametric data were compared between groups by analysis of variance and post hoc testing. Statistical significance was assumed if $P<0.05$. Multiple comparisons between the groups were performed using the $\mathrm{S}-\mathrm{N}-\mathrm{K}$ method. Nonparametric data were analysed using $\chi^{2}$ tests between groups. All statistical analyses were performed with the Statistical Package for Social Sciences (SPSS) software 13.0.

\section{Results}

Figure 1 shows the flowchart of the study design for the inclusion of patients. One hundred eighty patients underwent 3-port LC, and the $48 \mathrm{hr}$ post-LC evaluation period was considered for the final analysis.

There were no significant differences among the 3 groups with respect to age, weight, height, sex, ASA physical status, duration of surgery, awakening time from anesthesia, time to unassisted walking, sleep quality and number of patients experiencing PONV. In addition, we summarized the characteristics of patients who underwent elective LC and the distribution of 3 types of gallbladder disease observed in these patients (Table 1).

There were no significant differences in VAS scores and the consumption of dezocine among the three groups, but the VAS scores in the LAI group tended to be lower at all time points (Figure 2). However, patients receiving LAI at the trocar insertion sites expressed more satisfaction than patients in the other two groups $(P<0.001$, Figure 3$)$.

\section{Discussion}

Ortiz et al reported ${ }^{9}$ that bilateral ultrasound-guided TAPB is equivalent to incisional infiltration for overall postoperative pain in patients undergoing LC. In addition, subcostal TAPB could be considered preferable because it can be applied easily and in a shorter time. ${ }^{10}$ It is possible that TAPB could be more beneficial during conventional surgery. For this non-inferiority study, we concluded that there were no significant differences in VAS scores among the three groups; however, patients receiving LAI at the trocar insertion sites expressed more satisfaction than patients in whom other methods were used. Interestingly, we found a recent study supporting our conclusions. They reported ${ }^{11}$ that both TAPB and LAI shared a benefit in terms of primary outcomes for LC, and LAI was more effective for postoperative analgesia, easier to apply and safer than other analgesic methods. On the other hand, we did not find that ultrasound-guided posterior TAPB had an additional effect on reducing visceral pain, as reported previously. ${ }^{3}$

Ultrasound-guided TAPB was used for the treatment of pain after LC for the first time by El-Dawlatly et al in 2009. ${ }^{12}$ Since then, many other similar investigations have been performed. ${ }^{9,13-17}$ Clearly, the location of injection into the TAP alters the spread and effect of TAPB. Hebbard 


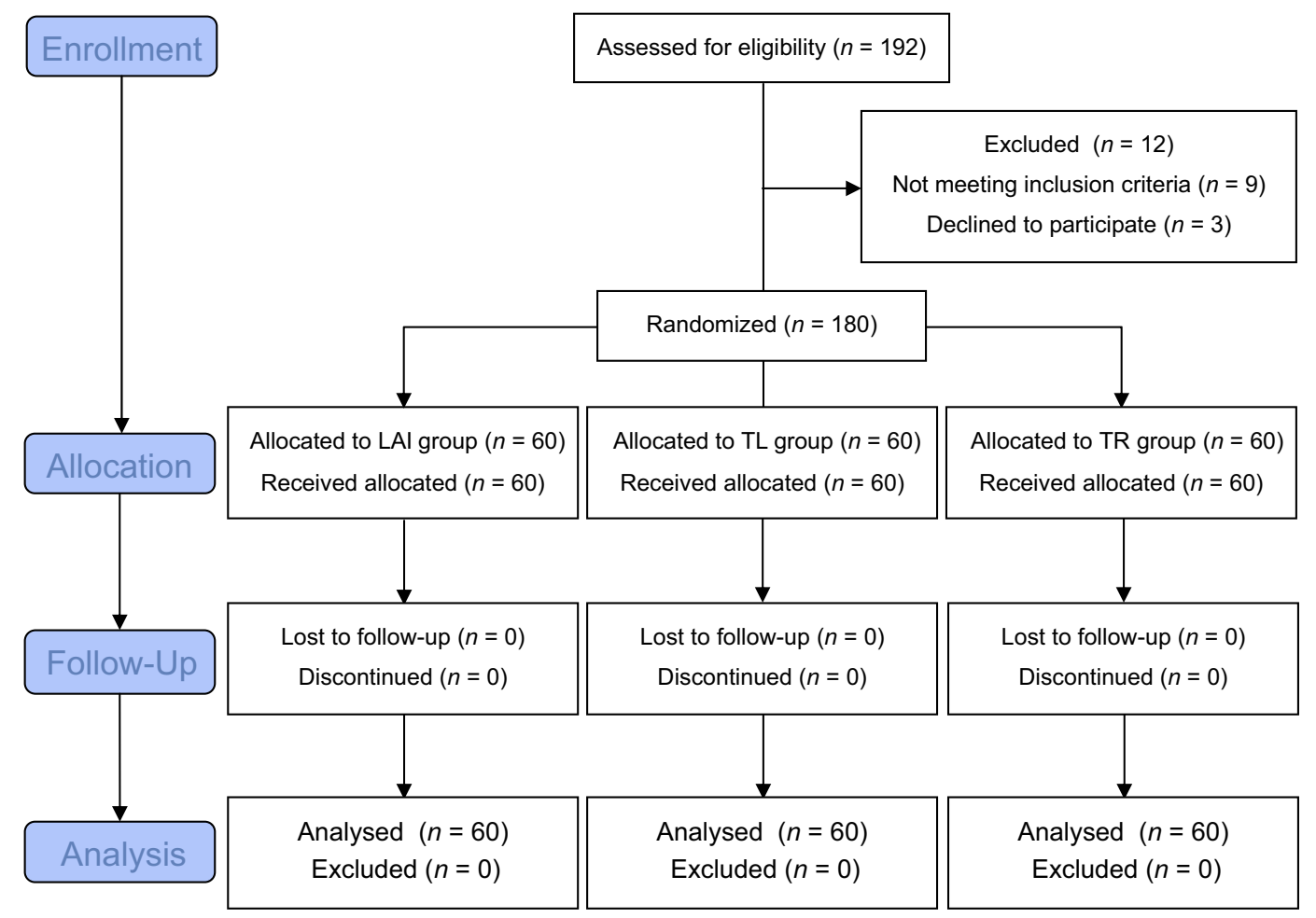

Figure I Consolidated Standards of Reporting Trials (CONSORT) flow diagram.

Table I Demographic characteristics of patients undergoing laparoscopic cholecystectomy (LC)

\begin{tabular}{|l|l|l|l|}
\hline & $\begin{array}{l}\text { Group LAl } \\
(\mathbf{n = 6 0 )}\end{array}$ & $\begin{array}{l}\text { Group TL } \\
(\mathbf{n = 6 0})\end{array}$ & $\begin{array}{l}\text { Group TR } \\
(\mathbf{n = 6 0})\end{array}$ \\
\hline Age (years) & $48.0 \pm 11.4$ & $47.6 \pm 10.1$ & $48.6 \pm 12.1$ \\
Weight (kg) & $65.5 \pm 7.9$ & $66.3 \pm 9.3$ & $64.5 \pm 9.3$ \\
Height (cm) & $163.5 \pm 5.8$ & $163.3 \pm 7.7$ & $163.7 \pm 7.4$ \\
Sex (female/male) & $19 / 41$ & $17 / 43$ & $20 / 40$ \\
ASA class (I/I) & $27 / 33$ & $29 / 31$ & $31 / 29$ \\
Duration of surgery (min) & $48.1 \pm 12.7$ & $46.5 \pm 10.6$ & $45.8 \pm 11.8$ \\
Awaking time of anesthesia (min) & $4.4 \pm 2.8$ & $4.5 \pm 2.6$ & $4.2 \pm 2.6$ \\
Time to unassisted walking (h) & $62.3 \pm 35.5$ & $60.3 \pm 25.6$ & $62.2 \pm 33.0$ \\
Waking up (yes/no) & $5 / 55$ & $7 / 53$ & $8 / 52$ \\
PONV (cases) & 5 & 7 & 6 \\
Gallstones with chronic cholecystitis & 56 & 55 & 55 \\
Gallstone & 1 & 2 & 1 \\
Gallbladder polyps & 3 & 3 & 4 \\
\hline
\end{tabular}

Notes: Data are presented as mean \pm SD or the number of patients. Group LAI = ropivacaine combining with dexmedetomidine infiltration and injection in incision sites, $\mathrm{TL}=$ ultrasound-guided posterior TAPB combined with LAI, TR = ultrasound-guided subcostal TAPB combined with RSB.

proposed that the range of TAP injections should be classified as follows: upper subcostal TAP (deep to the rectus, mainly covering T7 and T8); lower subcostal TAP (lateral to the rectus, mainly covering T9-11); lateral TAP (midway between the costal margin and the iliac crest along the midclavicular line, mainly covering T11 and T12). ${ }^{5}$ Another study showed that an ultrasound-guided TAP injection cephalad to the iliac crest is likely to involve the T10-L1 nerve roots and implied that the technique might be limited to use in lower abdominal surgery. ${ }^{18}$ Therefore, TAPB may have some beneficial effect in reducing pain and opioid requirements after LC, but this effect is likely small. ${ }^{13}$ Single-incision LC using an ultrasound-guided RSB significantly reduced postoperative pain. ${ }^{19}$ In addition, an RSB 


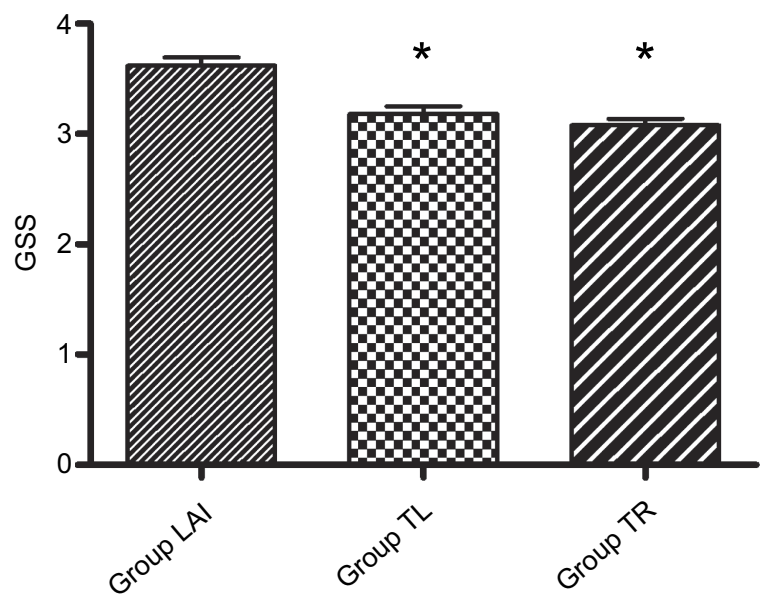

Figure 3 Global Satisfaction Score (GSS) within 48 hrs after laparoscopic cholecystectomy (LC). Data are presented as mean \pm SD. $* P<0.00$ I vs Group LAI. Group $\mathrm{LAI}=$ ropivacaine combining with dexmedetomidine infiltration and injection in incision sites, $\mathrm{TL}=$ ultrasound-guided posterior TAPB combined with LAI, TR = ultrasound-guided subcostal TAPB combined with RSB.
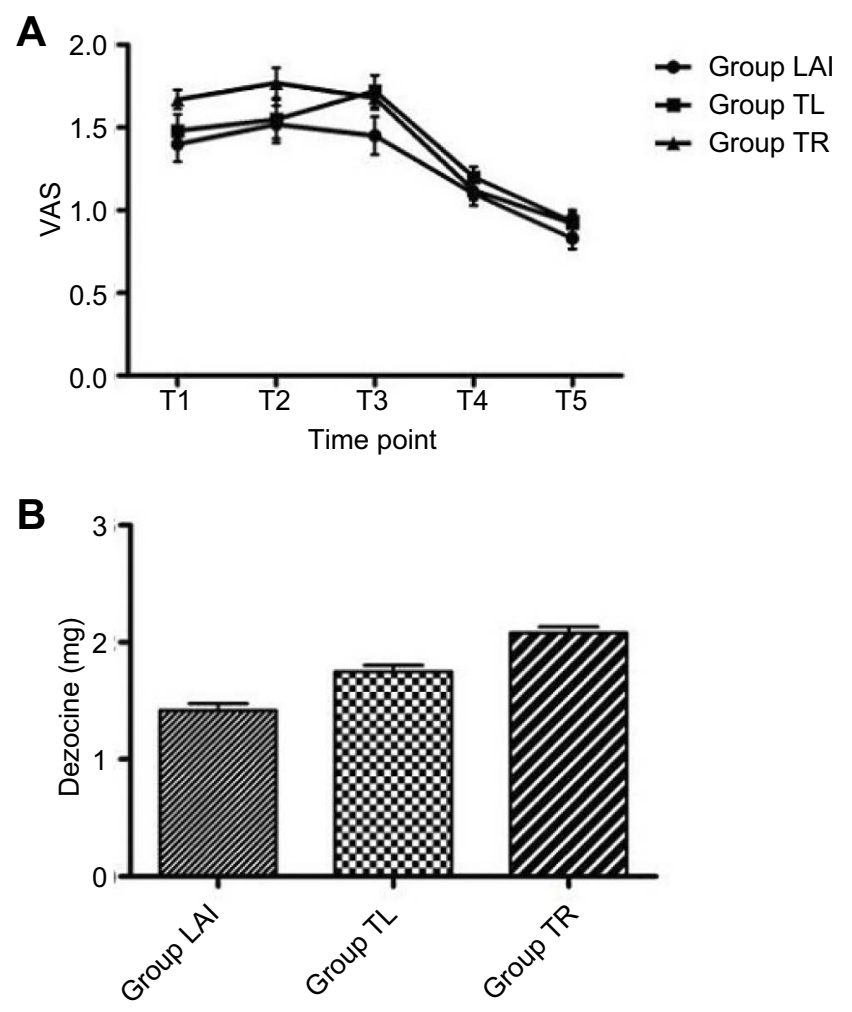

Figure 2 Postoperative Visual Analog Scale (VAS) score at different time point after laparoscopic cholecystectomy (LC) (A) and the total consumption of dezocine (B). Data are presented as mean \pm SEM. Group LAI = ropivacaine combining with dexmedetomidine infiltration and injection in incision sites, $\mathrm{TL}=$ ultrasoundguided posterior TAPB combined with LAI, TR = ultrasound-guided subcostal TAPB combined with RSB.

can provide analgesia for smack subxiphoid incisions along the course of $\mathrm{T} 6-\mathrm{T} 8,{ }^{4,5}$ which might be useful for pain control for incisions in the subxiphoid area. In our routine practice, the gallbladder is removed through a subxiphoid incision. Therefore, we emphasized pain relief for patients with subxiphoid incisions.

Adequately treating postoperative pain can decrease the opioid exposure risk and potentially prevent the diversion of excess medication for abuse. ${ }^{20}$ We reported that incisional infiltration of $150 \mathrm{mg}$ of ropivacaine combined with $1 \mu \mathrm{g} / \mathrm{kg}$ of dexmedetomidine was safe and efficient for postoperative pain relief after LC. ${ }^{7}$ Dexmedetomidine has many advantages as a multifaceted drug in perioperative medicine. ${ }^{21}$ Perineural dexmedetomidine added to ropivacaine provides an increased duration of analgesia and improves postoperative pain, ${ }^{22,23}$ and it was reported that the addition of dexmedetomidine to ropivacaine in TAPB had prolonged postoperative analgesia and reduced opioid consumption without any major adverse effects. ${ }^{24}$ Furthermore, dexmedetomidine administration also reduces the secretion of cytokines, leucocyte counts and C-reactive protein (CRP) levels, shifts the cytokine balance of $\mathrm{T}$ cells, and exhibits immunomodulatory effects after LC. ${ }^{25-27}$ The anti-inflammatory effects of dexmedetomidine can help to improve postoperative pain. Thus, we used dexmedetomidine in this study. To standardize the drug doses, the concentration of ropivacaine used in the peripheral nerve blocks in the abdominal wall groups was reduced by half. Further studies should confirm whether the GSS was influenced by the concentration of the drug. On the other hand, the volume of local anesthetic used in the LAI group of our protocol was $30 \mathrm{ml}$, which was more than that used in previous research. This volume could provide sufficient local blockade.

The use of short-acting anesthetics, such as remifentanil, has introduced a "fast-track anesthesia" concept in $\mathrm{LC}^{28}$ and a lower dose of remifentanil is equally effective in controlling stress hormones during LC. ${ }^{29}$ Thus, the time to unassisted walking in this study was shorter than that in previous research. However, a systematic review and meta-analysis reported that exposure to a high dose of short-acting remifentanil was associated with the development of hyperalgesia and led to significantly increased acute pain after surgery. ${ }^{30}$ However, this pain was efficiently alleviated or even prevented by dexmedetomidine or co-administration of flurbiprofen axetil. ${ }^{31}$ On the other hand, NSAIDs were recommended as a basic analgesic technique. ${ }^{32}$ In our study, flurbiprofen axetil might have been a promising method for attenuating opioid-induced hyperalgesia and postoperative pain. 
Several important factors influenced the outcome of this study. Firstly, the proficiency of minimally invasive surgery and the grasp of technical details were important; therefore, all of the 3-port LC procedures in this study were performed by professionally trained surgeons. Secondly, the ultrasound-guided peripheral nerve blocks of the abdominal wall were performed by anesthesiologists with significant experience, which could minimize or avoid possible errors in pain relieve. Finally, dezocine should be injected intramuscularly immediately once the VAS score $>3$ as this could affect the GSS.

There are several limitations to our study. For example, there was no correct assessment of the success rate of the ultrasound-guided peripheral nerve blocks of the abdominal wall as it was performed after the induction of general anesthesia and not by the same operator; however, we relied on the skills of the investigators and the use of ultrasound to accurately place the blocking needle according to the report by Sarvesh et $\mathrm{al}^{24}$. Another limitation is that it has been reported ${ }^{33}$ that ultrasound-guided erector spinae plane blocks (ESPBs) reduce postoperative analgesic use and pain scores more effectively than oblique subcostal TAPB after LC. Therefore, further welldesigned studies are needed to confirm the differences between ESPB and LAI for patients undergoing LC.

\section{Conclusion}

Ultrasound-guided peripheral nerve blocks of the abdominal wall can significantly relieve postoperative pain in patients undergoing LC; however, patients receiving LAI expressed more satisfaction than patients in whom other methods were used. LAI is an easy and effective method that can be recommended for routine clinical practice in LC patients who are not converted to an open procedure.

\section{Ethical statement}

The authors declare that all the patients provided written informed consent and that this study was conducted in accordance with the Declaration of Helsinki. The study was approved by the Institutional Research Ethics Committee of The First People's Hospital of Hefei (No. 2015-11).

\section{Data sharing statement}

The authors will allow sharing of participant data. The data will be available for anyone who wishes to access them for any purpose. The data will be accessible from immediately following publication to 6 months after publication, and contact should be made via the principal investigator majuny163@163.com.

\section{Acknowledgments}

This work is supported by a medical research project sponsored by the Health and Family Planning Commission of Hefei (No: hwk2016yb002).

\section{Author contributions}

All authors contributed to data analysis, drafting or revising the article, gave final approval of the version to be published, and agree to be accountable for all aspects of the work.

\section{Disclosure}

The authors report no conflicts of interest in this work.

\section{References}

1. Rosero EB, Joshi GP. Hospital readmission after ambulatory laparoscopic cholecystectomy: incidence and predictors. J Surg Res. 2017;219:108-115. doi:10.1016/j.jss.2017.05.071

2. Khan KK, Khan RI. Analgesic effect of bilateral subcostal tap block after laparoscopic cholecystectomy. J Ayub Med Coll Abbottabad. 2018;30(1):12-15.

3. Taketa Y, Fujitani T, Irisawa Y, et al. Comparison of analgesic efficacy between posterior and lateral transversus abdominis plane block techniques for laparoscopic gynecological surgery. Masui. 2015;64(10):1015-1022.

4. Hebbard PD, Barrington MJ, Vasey C. Ultrasound-guided continuous oblique subcostal transversus abdominis plane blockade: description of anatomy and clinical technique. Reg Anesth Pain Med. 2010;35 (5):436-441.

5. Hebbard P. TAP block nomenclature. Anaesthesia. 2015;70 (1):112-113. doi:10.1111/anae.12970

6. Iwata M, Kuzumoto N, Kmoto K, et al. Effects of RSB and TAPB on postoperative pain in laparoscopic cholecystectomy. Masui. 2017;66 (2):127-130.

7. Yu JM, Sun $\mathrm{H}, \mathrm{Wu} C$, et al. The analgesic effect of ropivacaine combined with dexmedetomidine for incision infiltration after laparoscopic cholecystectomy. Surg Laparosc Endosc Percutan Tech. 2016;26(6):449-454. doi:10.1097/SLE.0000000000000325

8. Pang WW, Mok MS, Lin CH, et al. Comparison of patient-controlled analgesia (PCA) with tramadol or morphine. Can J Anaesth. 1999;46 (11):1030-1035. doi:10.1007/BF03013197

9. Ortiz J, Suliburk JW, Wu K, et al. Bilateral transversus abdominis plane block does not decrease postoperative pain after laparoscopic cholecystectomy when compared with local anesthetic infiltration of trocar insertion sites. Reg Anesth Pain Med. 2012;37(2):188-192. doi:10.1097/AAP.0b013e318244851b

10. Baytar C, Yilmaz C, Karasu D, et al. Comparison of ultrasound-guided subcostal transversus abdominis plane block and quadratus lumborum block in laparoscopic cholecystectomy: a prospective, randomized, controlled clinical study. Pain Res Manag. 2019;3:2815301. 
11. Molfino S, Botteri E, Baggi P, et al. Pain control in laparoscopic surgery: a case-control study between transversus abdominis plane-block and trocar-site anesthesia. Updates Surg. 2018. Epub ahead of print. doi:10.1007/s13304-018-00615-y

12. El-Dawlatly AA, Turkistani A, Kettner SC, et al. Ultrasound-guided transversus abdominis plane block: description of a new technique and comparison with conventional systemic analgesia during laparoscopic cholecystectomy. $B r \quad J$ Anaesth. 2009;102(6):763-767. doi:10.1093/bja/aep067

13. Petersen PL, Stjernholm P, Kristiansen VB, et al. The beneficial effect of transversus abdominis plane block after laparoscopic cholecystectomy in day-case surgery: a randomized clinical trial. Anesth Analg. 2012;115(3):527-533.

14. Kokulu S, Bakı ED, Kaçar E, et al. Effect of transversus abdominis plane block on cost of laparoscopic cholecystectomy anesthesia. Med Sci Monit. 2014;20:2783-2787. doi:10.12659/MSM.892055

15. Bhatia N, Arora A, Wig J, et al. Comparison of posterior and subcostal approaches to ultrasound-guided transverse abdominis plane block for postoperative analgesia in laparoscopic cholecystectomy. J Clin Anesth. 2014;26(4):294-299. doi:10.1016/j.jclinane.2013.11.023

16. Shin HJ, Oh AY, Baik JS, et al. Ultrasound-guided oblique subcostal transversus abdominis plane block for analgesia after laparoscopic cholecystectomy: a randomized, controlled, observer-blinded study. Minerva Anestesiol. 2014;80(2):185-193.

17. Saliminia A, Azimaraghi O. Babayipour S, et al. Efficacy of transverse abdominis plane block in reduction of postoperation pain in laparoscopic cholecystectomy. Acta Anaesthesiol Taiwan. 2015;53 (4):119-122. doi:10.1016/j.aat.2015.07.003

18. Tran TM, Ivanusic JJ, Hebbard P, Barrington MJ. Determination of spread of injectate after ultrasound-guided transversus abdominis plane block: a cadaveric study. Br J Anaesth. 2009;102(1):123-127. doi:10.1093/bja/aen344

19. Kamei H, Ishibashi N, Nakayama G, et al. Ultrasound-guided rectus sheath block for single-incision laparoscopic cholecystectomy. Asian J Endosc Surg. 2015;8(2):148-152. doi:10.1111/ases.12178

20. Hartford LB, Van Koughnett JAM, Murphy PB, et al. Standardization of Outpatient Procedure (STOP) narcotics: a prospective non-inferiority study to reduce opioid use in outpatient general surgical procedures. J Am Coll Surg. 2019;228(1):81-88e1. doi:10.1016/ j.jamcollsurg.2018.09.008

21. Farag E. Dexmedetomidine: a multifaceted drug in perioperative medicine. $J$ Clin Anesth. 2018;55:1-2. doi:10.1016/j. jclinane.2018.12.015

22. Brummett CM, Hong EK, Janda AM, et al. Perineural dexmedetomidine added to ropivacaine for sciatic nerve block in rats prolongs the duration of analgesia by blocking the hyperpolarization-activated cation current. Anesthesiology. 2011;115(4):836-843. doi:10.1097/ ALN.0b013e318221fcc 9
23. Fritsch G, Danninger T, Allerberger $\mathrm{K}$, et al. Dexmedetomidine added to ropivacaine extends the duration of interscalene brachial plexus blocks for elective shoulder surgery when compared with ropivacaine alone: a single-center, prospective, triple-blind, randomized controlled trial. Reg Anesth Pain Med. 2014;39(1):37-47. doi:10.1097/AAP.0000000000000033

24. Sarvesh B, Shivaramu BT, Sharma K, et al. Addition of dexmedetomidine to ropivacaine in subcostal transversus abdominis plane block potentiates postoperative analgesia among laparoscopic cholecystectomy patients: a prospective randomized controlled trial. Anesth Essays Res. 2018;12(4):809-813. doi:10.4103/ aer.AER 14118

25. Kang SH, KiM YS, Hong TH, et al. Effects of dexmedetomidine on inflammatory responses in patients undergoing laparoscopic cholecystectomy. Acta Anaesthesiol Scand. 2013;57(4):480-487. doi:10.1111/aas.12039

26. Kim Y, Kang SH, Hong TH, et al. Effects of dexmedetomidine on the ratio of $\mathrm{T}$ helper 1 to $\mathrm{T}$ helper 2 cytokines in patients undergoing laparoscopic cholecystectomy. J Clin Anesth. 2014;26(4):281-285. doi:10.1016/j.jclinane.2013.11.018

27. Lee JM, Han HJ, Choi WK, et al. Immunomodulatory effects of intraoperative dexmedetomidine on $\mathrm{T}$ helper $1, \mathrm{~T}$ helper $2, \mathrm{~T}$ helper 17 and regulatory $\mathrm{T}$ cells cytokine levels and their balance: a prospective, randomised, double-blind, dose-response clinical study. BMC Anesthesiol. 2018;18(1):164. doi:10.1186/s12871-018-0540-6

28. Çaparlar CÖ, Özhan MÖ, Süzer MA, et al. Fast-track anesthesia in patients undergoing outpatient laparoscopic cholecystectomy: comparison of sevoflurane with total intravenous anesthesia. J Clin Anesth. 2017;37:25-30. doi:10.1016/j.jclinane.2016.10.036

29. Sessa F, Levantesi L, Congedo E, et al. Effect of different doses of remifentanil on stress response during laparoscopic cholecystectomy. J Opioid Manag. 2019;15(1):43-49.

30. Fletcher D, Martinez V. Opioid-induced hyperalgesia in patients after surgery: a systematic review and a meta-analysis. $\mathrm{Br} J$ Anaesth. 2014;112(6):991-1004. doi:10.1093/bja/aeu137

31. Yu Z, Wu W, Wu X, et al. Protective effects of dexmedetomidine combined with flurbiprofen axetil on remifentanil-induced hyperalgesia: A randomized controlled trial. Exp Ther Med. 2016;12(4):2622-2628.

32. Barazanchi AWH, MacFater WS, Rahiri JL, et al. Evidence-based management of pain after laparoscopic cholecystectomy: a PROSPECT review update. Br J Anaesth. 2018;121(4):787-803. doi:10.1016/j.bja.2018.06.023

33. Altiparmak, B, Korkmaz Toker M, Uysal AI, et al. Ultrasoundguided erector spinae plane block versus oblique subcostal transversus abdominis plane block for postoperative analgesia of adult patients undergoing laparoscopic cholecystectomy: randomized, controlled trial. J Clin Anesth. 2019;57:31-36. doi:10.1016/j. jclinane.2019.03.012
Journal of Pain Research

\section{Publish your work in this journal}

The Journal of Pain Research is an international, peer reviewed, open access, online journal that welcomes laboratory and clinical findings in the fields of pain research and the prevention and management of pain. Original research, reviews, symposium reports, hypothesis formation and commentaries are all considered for publication. The manuscript management system is completely online and includes a very quick and fair peer-review system, which is all easy to use. Visit http:// www.dovepress.com/testimonials.php to read real quotes from published authors. 